\begin{tabular}{|c|c|c|}
\hline & Int.J.Curr.Microbiol.App.Sci (2021) 10(11): 89-96 & \\
\hline & $\begin{array}{l}\text { International Journal of Current Microbiology and Applied Sciences } \\
\text { ISSN: 2319-7706 Volume } 10 \text { Number } \mathbf{1 1}(\mathbf{2 0 2 1 )} \\
\text { Journal homepage: } \underline{\text { http://www.ijcmas.com }}\end{array}$ & $\$$ \\
\hline $\begin{array}{l}\text { EXCELLENT } \\
\text { PUBLISHERS }\end{array}$ & & \\
\hline
\end{tabular}

\title{
Anti-bacterial Efficacy of WHO Recommended Locally made Alcohol based Hand Rub in a Resource Constraint Environment
}

\author{
Krishnan Usha Krishnan ${ }^{1 *}$, Navaneethakrishnan Rathnapriya ${ }^{2}$ and David Agatha $^{3}$ \\ ${ }^{1}$ Government Kilpauk Medical College, Tamil Nadu, India \\ ${ }^{2}$ Government Omandurar Medical College, Tamil Nadu, India \\ ${ }^{3}$ Government Stanley Medical College, Tamil Nadu, India \\ *Corresponding author
}

\section{A B S T R A C T}

Keywords

Healthcare-

associated

infections,

Hand hygiene,

Alcohol based hand

rub and Intensive

Medical Care Unit

Article Info

Received:

02 October 2021

Accepted:

30 October 2021

Available Online:

10 November 2021
Healthcare-associated infections (HCAIs) are a major concern and associated with noticeable morbidity and mortality. To combat this, the simple strategy is hand hygiene $(\mathrm{HH})$. In a resource constraint settings one of the important reason for poor hand hygiene compliance is irregular supply of $\mathrm{HH}$ products. This study was done to assess the cost effectiveness and acceptability of WHO recommended locally made alcohol based hand rub. The study was carried out in 28 HCPs working in an IMCU. Samples for the assessment of the microbial hand contamination were collected by direct fingerprint of their dominant hand onto the blood agar plates at three different time point. Group A samples collected in random. Group B samples collected immediately after patient physical examination. Group C were group B representatives collected after cleaning their hands with locally made isopropyl alcohol based hand rub. No significant difference in colony count between the groups A and B was observed. On the other hand, there was a statistically significant difference in colony count between the groups $\mathrm{B}$ and $\mathrm{C}(\mathrm{P}=0.05)$. It means that the rubbing of the hands using locally made WHO recommended hand sanitizer enabled to eradicate the bacterial flora remarkably from the hands of HCPs.

\section{Introduction}

Healthcare-associated infections (HCAIs) are a major concern for the patients globally and are associated with noticeable morbidity and mortality (1). The other impacts of HCAI includes long-term disability, increased microbial resistance due to prolonged hospital stay, unnecessary financial burden and excess death (2). Diagnosis of HCAI is complex because of the difficulty in gathering reliable diagnostic data across the world. Only a few studies from the developing countries such as Tanzania and India reported about the assessment of HCAI risk factors through multivariate analysis $(3,4)$. Considering the 
consequences of HCAIs globally, it is highly recommended to adopt various preventive measures to HCAIs within the affordable and simplified resources. But, technically it is not possible at least in developing countries because of the limited resources and data sources.

$\mathrm{HH}$ (Hand Hygiene) is considered as an important indicator of the safety and the quality of care delivered in any health-care setting and is emphasized in the WHO Collaborating Centre on Patient Safety Solutions as one of the highest priority solutions to improve patient safety (5). Only a few studies demonstrated about the improvement of hand hygiene through the use of alcohol-based gels along with the active educational programmes (6). In the present catastrophic situation, so many commercial manufacturing units developed alcohol based hand sanitizers with the labels on package claiming $99.5 \%$ of germs killing towards the progression of SARS-COVID19 pandemic prevention. Not only is the quality of the presently available market sanitizer is a big question, but also the price and the nonavailability of resources due to the pandemic restrictions. On this background, this particular study was performed to evaluate the anti-bacterial efficacy and the cost effectiveness of WHO recommended locally made alcohol based hand rub.

\section{Materials and Methods}

\section{Study Design}

The study was carried out in 28 HCPs including doctors, staff nurses, interns and attenders working in an IMCU of Madras Medical College, Chennai, Tamil Nadu, India. Samples for the assessment of the microbial hand contamination were collected by asking the HCPs to make a direct fingerprint of their hand onto the blood agar plates at three different time point. The study consists of three groups. Group A consists of the collection of direct fingerprints of HCPs working at IMCU in random. Group B consists of fingerprints of HCPs collected immediately after patient physical examination. Group $\mathrm{C}$ consists of fingerprints of group B representatives collected after cleaning their hands with locally made isopropyl alcohol based hand rub after patient physical examination. Isopropyl alcohol based hand rub was prepared as per the guideline to produce local alcohol based hand rubs recommended by WHO (7). The composition and the volume of the products are given in Table 1.

\section{Study Procedure}

Each health care providers were asked to apply $2 \mathrm{~mL}$ of isopropyl alcohol based hand rub product on their palms. Specific oral instructions as well as the demonstration about the various steps of hand rubbing movements as per the instructions of WHO was given to all the participants (8). Each subject was allowed to perform the same sequences of hand rubbing motions and ensured that the entire hand surface was covered with the product. More importantly, the samples were collected allowing the complete dryness of the hands after the application with locally made alcohol-based hand rubs. After 12 hours of incubation, the bacterial colonies per plate were counted from each samples based on the standard microbiological techniques. Antibiotic susceptibility test was performed by Kirby Bauer method in order to find out the resistance pattern according to Clinical Laboratory Standard Institution Guidelines.

\section{Statistical analysis}

The Wilcoxon signed rank test was used for the statistical analysis and the $\mathrm{p}$ value of 0.05 is considered to denote the significant level. 


\section{Results and Discussion}

The skin of the human body consists of a diverse milieu of harmless microorganisms. They are generally considered as nonpathogenic and harmless saprophytes while the other microorganisms are considered as potential pathogens to human (9). Fifteen participants from the group B $(53 \%)$ are reported with the presence of pathogenic bacteria on their hands immediately after patient physical examination. Among the 15 participants from group B, three of them were identified with the presence of Klebsiella pneumoniae, one with Acinetobacter spp and the remains (11 participants) were with Staphylococcus aureus. Almost $63 \%$ of the latter participants (11 participants) are found to contaminate with MRSA. Figure 1 represents the images of dominant hand finger imprints of HCPs collected on the blood agar medium. The median and the interquartile range analysis of colony count from the finger imprint of HCPs were given in table 2. The colony forming units (CFU) median counts in agar plates is compared by the null hypothesis test. Wilcoxon signed rank test was used for the statistical analysis. There were no significant statistical difference was found between the groups $\mathrm{A}$ and $\mathrm{B}$ with respect to the bacterial colony count (Table 3). On the other hand, a statistically significant reduction in the colony count was observed between the groups C and B (Table 4). Figure 2 represents the graphical description of the data. The graph denotes a significant reduction in the mean colony count of those HCPs whose hands were rubbed with locally made isopropyl based hand rub immediately after patient physical examination admitted at ICMU. Altogether, our data emphasize that the locally made isopropyl based hand rub is efficient enough to reduce the flora of the pathological microorganisms from the hands and its transfection from person to person in a health care system. Thus, the data support that the locally made alcohol based hand rub made as per WHO recommendation is sufficient enough to prevent HCAIs between HCPs and patients and also among the patients.

Centuries ago, hand washing procedure with soap and water has been embedded within religious and cultural habits as a tool to maintain personal hygiene and also as a preventive measure to avoid pathogenic transmission $(10,11)$. It was only 2 centuries ago, the link between hand washing and the spread of disease was established among the HCPs. Numerous studies reported that the hands of HCPs plays an important role in the propagation of pathogenic microorganisms within the health care environment $(12,8,13)$. More than 1.4 million patients both from the developed and developing countries are reporting with HCAIs at any time of hospital admission (14). The magnitude of HCAIs problem is more in developing countries due to many issues such as poor hygiene and sanitation, understaffing shortage or lack of sufficient basic equipment, overcrowding, malnutrition and finally due to limited financial resources $(15,16)$. The burden of HCAI is found to be more severe in high-risk population such as in neonates and also in adults housed in ICUs (17). Reduction in HCAI impact is possible only through the implementation of evidence-based measures and also through generating the hospital epidemiology knowledge among the HCPs especially those who are working in IMCU (18).

In the present study found that among the total representatives from the group B, three of them are reported with the presence of of Klebsiella pneumoniae and one with Acinetobacter spp. 
Table.1 Composition of alcohol based hand rub formulation based on WHO recommendation

\begin{tabular}{|c|c|c|c|}
\hline Content & Percentage & Concentration & Volume \\
\hline Isopropyl Alcohol & $99.8 \%$ & $75 \% \mathrm{v} / \mathrm{v}$ & $751.5 \mathrm{~mL}$ \\
\hline Hydrogen Peroxide & $3 \%$ & $1.45 \% \mathrm{v} / \mathrm{v}$ & $41.7 \mathrm{~mL}$ \\
\hline Glycerol & $98 \%$ & $0.125 \% \mathrm{v} / \mathrm{v}$ & $14.5 \mathrm{~mL}$ \\
\hline
\end{tabular}

Make the total volume up to $1000 \mathrm{~mL}$ by adding distilled water or boiled and cooled water. Shake the flask gently to mix the content eventually.

Table.2 Colony count obtained from various sample categories

\begin{tabular}{|c|c|}
\hline Sample Category & Median colony count (interquartile range) \\
\hline $\begin{array}{c}\text { Group-A } \\
\text { Samples collected from HCP randomly }\end{array}$ & $114.5(188.25)$ \\
\hline $\begin{array}{c}\text { Group-B } \\
\text { Samples collected from HCP after } \\
\text { patient physical examination }\end{array}$ & $63(84.75)$ \\
\hline $\begin{array}{c}\text { Group-C } \\
\text { Samples of group B representatives } \\
\text { collected after the use of hand rub }\end{array}$ & $6(13)$ \\
\hline
\end{tabular}

Table.3 Statistical analysis between Group A and B samples

\begin{tabular}{|c|c|c|c|}
\hline Null Hypothesis & Test & Significance & Decision \\
\hline $\begin{array}{c}\text { Median Differences between } \\
\text { Group A and B is equal to Zero }\end{array}$ & $\begin{array}{c}\text { Related samples } \\
\text { Wilcoxon Singed Rank } \\
\text { Test }\end{array}$ & 0.882 & $\begin{array}{c}\text { Retain the Null } \\
\text { Hypothesis }\end{array}$ \\
\hline
\end{tabular}

The significance level is 0.05 .

Table.4 Statistical analysis between Group B and C samples

\begin{tabular}{|c|c|c|c|}
\hline Null Hypothesis & Test & Significance & Decision \\
\hline $\begin{array}{c}\text { Median Differences between } \\
\text { Group B and Cis equal to Zero }\end{array}$ & $\begin{array}{c}\text { Related samples } \\
\text { Wilcoxon Singed Rank } \\
\text { Test }\end{array}$ & 0.000 & $\begin{array}{c}\text { Reject the Null } \\
\text { Hypothesis }\end{array}$ \\
\hline
\end{tabular}

The significance level is 0.05 . 
Fig.1A Images of finger imprints of health care providers collected on blood agar medium

A - 1

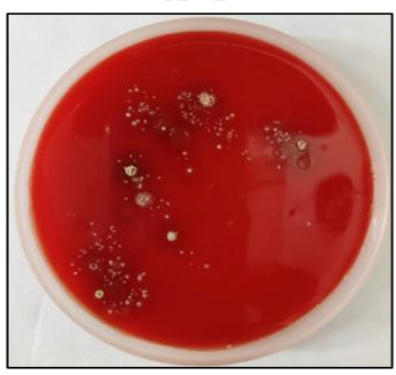

B - 1

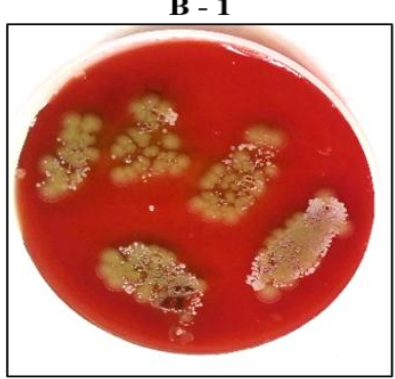

C - 1

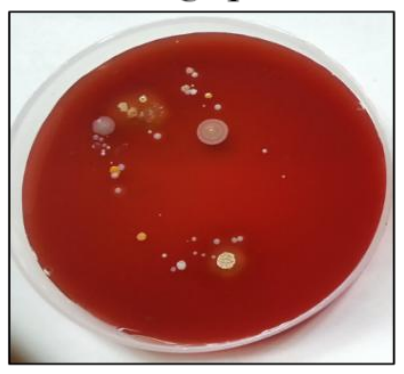

A - 2

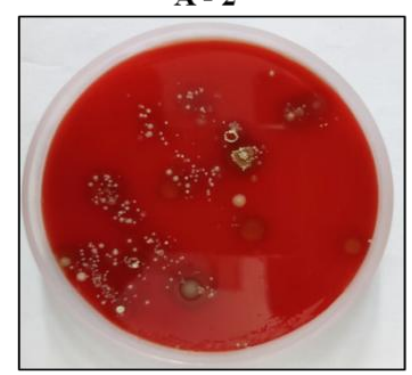

B - 2

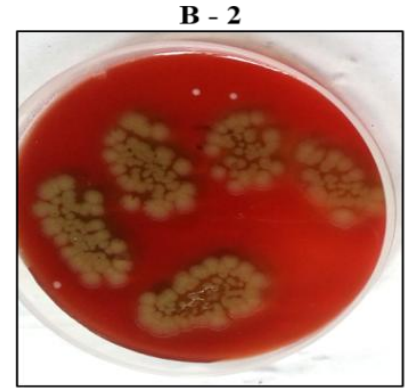

C - 2

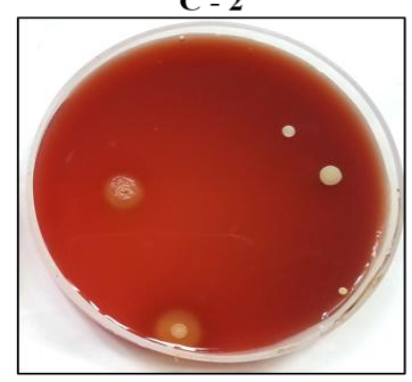

Figure.1B Comparison of colony count of different sample categories

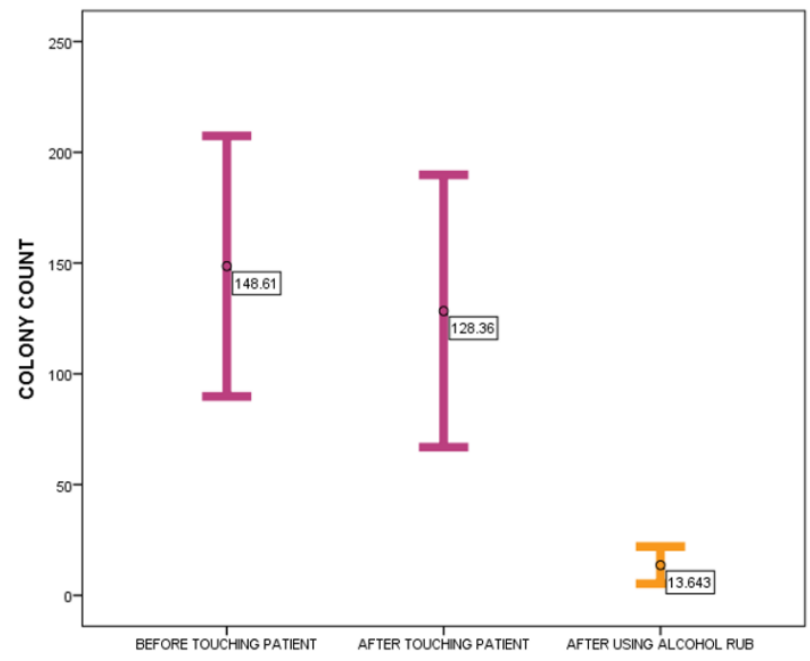


While the others are reported with Staphyloccocus aureus, almost $63 \%$ of the 11 members from the group B are found to be contaminated with MRSA. In healthcare facilities, the risk of more serious Staphylococcus infections is higher for those patients who are admitted in ICUs. We found that, almost $73 \%$ of the group B participant's hands were contaminated with S.aureus. The data speculated that the hand contamination rates among the HCPs due to $S$. aureus is 10 to $78 \%$ more than that of other micro pathogens.

We have not found any significant difference in colony count between the groups A and B. This inferences indicates that the microbial hand contamination of HCPs working in IMCU assessed at any random time is equal or higher than after the physical examination of patients admitted at IMCU. Reasons behind this scenario includes poor adherence of hand hygiene practise by HCPs as well as the heavy microbial load in the environment. Our inference is similar to the previously reported data in which the participants without hand wash prior to the patient physical examination showed higher number of bacteria than the participants with hand wash prior to patient physical examination (18). On the other hand, we found a statistically significant difference in colony count between the groups $\mathrm{B}$ and $\mathrm{C}$ $(\mathrm{P}=0.05)$. It means that the rubbing of the hands using locally made isopropyl alcohol based hand sanitizer enabled to eradicate the bacterial flora remarkably from the hands of HCPs. Our finding speculated that the locally made hand wash as per WHO recommendation is found to be more effective in reducing the pathogenic flora from the hands of HCPs significantly and thereby a reduction in the cross contamination of pathogens and HCAIs rate in a health care environment. Isopropyl alcohol based hand formulation is 8 to 10 times more cost effective than the similar preparations available commercially. None of the participants were reported with any kind of skin allergic reactions. Feedback data about the product by the users were obtained using WHO Multimodal Hand Hygiene Improvement Strategy Analysis and the WHO Questionnaire on Ward Structure for Hand Hygiene (Implementation Toolkit, available at http://www.who.int/gpsc/en/).The long term compliances about the product were not able to collect in details since, the study performed in a single time point. More importantly, we recommend that one has to strictly adhere with the safety measures while considered the production of alcohol based hand rub in large scale on regular basis.

Rubbing of hands using alcohol based hand rubs prepared as per WHO recommendation is an effective strategy to prevent the transmission of HCAIs through the hands of HCPs. The microbial hand contamination of HCPs working at IMCU setting is high when they are not adhered to $\mathrm{HH}$ procedure before and after the physical examination of patients. Maintenance of $\mathrm{HH}$ with the use of locally made isopropyl based hand rub is enable to reduce the number of pathogenic bacterial colonies from the HCPs hands significantly.

The preparation of alcohol based hand rub as per WHO recommendation is highly cost effective and is acceptable. Isopropyl alcohol based locally made hand rub is an ideal recommendation in a resource constraint setting if the safety and the quality control measures are adhered properly.

The study and its outcome are more relevant in the present COVID-19 pandemic scenario where the maintenance of hand hygiene is considered as one of the effective measures to prevent the transmission of SARS-CoV2 virus. Since, the WHO recommended alcohol 
based hand rub preparation procedure is simple, cost effective along with remarkable efficiency, we advised to use the same not only for the prevention HCAIs at health care environment, but also by each and every individuals towards the prevention of COVID19 virus globally.

\section{References}

1. Klevens R M, Edwards J R, Richards C L Jr, Horan T C, Gaynes R P, Pollock D A, Cardo D M. Estimating health careassociated infections and deaths in U.S. hospitals, 2002. Public Health Rep 2007;122(2):160-6. doi: $10.1177 / 003335490712200205$

2. WHO 2006 World Alliance for Patient Safety. The Global Patient Safety Challenge 2005-2006 "Clean Care is Safer Care". Geneva, World Health Organization, 2005 (http://www.who.int/gpsc/ en/, accessed 1 December 2008).

3. WHO 2007 Patient Safety Solutions 2007. Geneva, World Health Organization 2007. www.who.int/patientsafety/solutions/patie ntsafety/en/.

4. Harbarth S, Pittet D, Grady L, Zawacki A, Potter-Bynoe G, Samore M H, Goldmann D A. Interventional study to evaluate the impact of an alcohol-based hand gel in improving hand hygiene compliance. Pediatr Infect Dis J 2002; 21(6):489-95. doi: 10.1097/00006454-200206000-00002.

5. WHO 2020. http://www.who.int/ gpsc/5may/Guide_to_Local_Production, 2010. Geneva, World Health Organization 2010.

6. WHO 2006. WHO Guidelines on Hand Hygiene in Health Care (Advanced Draft) Geneva: World Health Organization, World Alliance for Patient Safety. 2006.

7. Grice E A, Segre J A. The skin microbiome. Nat Rev Microbiol2011; 9(4):244-53. doi: 10.1038/nrmicro2537.
8. Rotter M. Hand washing and hand disinfection. In: Mayhall CG, ed. Hospital epidemiology and infection control, 2nd ed. Philadelphia, PA, Lippincott Williams \& Wilkins, 1999; 1339-1355.

9. Jumaa P A. Hand hygiene: simple and complex. International Journal of Infectious Diseases 2005; 9:3-14.

10. Allegranzi B, Pittet D. Role of hand hygiene in healthcare-associated infection prevention. Journal of Hospital Infection2009; 73:305-315. doi:10.1016/j.jhin.2009.04.019

11. Pittet D, Allegranzi B, Sax H, Dharan S, Pessoa-Silva C L, Donaldson L, Boyce J $\mathrm{M}$; Evidence-based model for hand transmission during patient care and the role of improved practices Lancet Infect Dis. 2006; 6(10):641-52. doi: 10.1016/S1473-3099(06)70600-4.

12. Allegranzi B, Bagheri Nejad S, Attar H, Graafmans W, Pittet D. The burden of hospital-acquired infections (HAI) in developing countries: a systematic review. Poster presented at: 48th Inter-science Conference on Antimicrobial Agents and Chemotherapy/46th Annual Meeting of the Infectious Diseases Society of America, Washington, DC, 2008, abstr. K-4106.

13. National Nosocomial Infections Surveillance (NNIS) System Report, data summary from January 1992 through June 2004. American Journal of Infection Control 2004: 32:470-485.

14. Panousi M N, Williams G J, Girdlestone S, Hiom S J, Maillard J Y. Evaluation of Alcohol Wipes Used During Aseptic Manufacturing. Society for Applied Microbiology. Letters ApplMicrobiol 2009; 48:648-51.

15. Pohle W D, Stuart L S. The germicidal action of cleaning agents - a study of a modification of Price's procedure. J Infect Dis 1940;67:275-81.

16. Netsvyetayeva I, Marusza W, Olszanski R, Szyller K, Krolak-Ulinska A, Swoboda- 
Kopec E, Sierdzinski J, Szymonski Z, Mlynarczyk G. Skin bacterial flora as a potential risk factor predisposing to late bacterial infection after cross-linked hyaluronic acid gel augmentation. Infect Drug Resist 2018;11:213-222

17. Mathai E, Allegranzi B, Kilpatrick C, Pittet D. Prevention and control of health care-associated infections through improved hand hygiene. Indian $\mathrm{J}$ Med Microbiol 2010;28:100-6

18. Nogueras M, Marinsalta N, Roussell M, Notario R. Importance of hand germ contamination in health-care workers as possible carriers of nosocomial infections. Revista do Instituto de Medicina Tropical de São Paulo 2001; 43: 149-52. 10.1590/S0036-46652001000300006.

\section{How to cite this article:}

Krishnan Usha Krishnan, Navaneethakrishnan Rathnapriya and David Agatha. 2021. Antibacterial Efficacy of WHO Recommended Locally made Alcohol based Hand Rub in a Resource Constraint Environment. Int.J.Curr.Microbiol.App.Sci. 10(11): 89-96. doi: https://doi.org/10.20546/ijcmas.2021.1011.012 